\title{
Blended Learning: Past and Present with Special Reference to COVID-19 Pandemic
}

\author{
Aisha Shams Akhunzada \\ Ph.D Scholar,Fatima Jinnah Women University Rawalpindi \\ aishashams89@gmail.com \\ Isharat Siddiqua Lodhy \\ Assitant Professor,Department of Education,Fatima Jinnah women university Rawalpindi \\ ishratsiddiqa@fjwu.edu.pk \\ Parveen Munshi \\ Vice Chancellor, University of Sufism and modern technology Sindh \\ munshiparveen@gmail.com \\ Sakina Jumani \\ Lecturer, University of Sufisim and modern technology Sindh \\ sakinajumani00@gmail.com
}

\begin{abstract}
The Clayton Christensen academy describes blended learning as a structured educational program in which a student learns at least in part into internet-based content delivery and training with some characteristic of academic supervision from home. This process involved time, place, pattern, and careful monitoring facilities. It also encouraged the learners to feel more optimistic regarding their studies. The fundamental concept of driving blended learning is that it encourages a combination of self-learning and collective communication-oriented practices. However, during COVID-19 besides virtual and nonformal institutions, the formal educational institutes also moved to blended learning. As this was a new practice for the formal instructors and learners, therefore, this study was carried out for discovering the concept of blended learning with special reference to COVID-19 pandemic and for this reason three sub purposes were; shed light on the concept of blended learning; to describe terminologies used for blended learning in the past and present with special reference to COVID-19 pandemic and to discover blended learning strategies in the past and presnt with special reference to COVID-19. This study chartered a qualitative method with succeeding in the analysis of documents related to blended learning and how this strategy was used during COVID -19 for engaging the formal instructors with their students. The Study followed the five years documents available online since 2011-20. But some documents from 2021 were also viewed for methodology. The researchers' inquiry into 10 years of data was for the purpose to discover the past strategies of blended learning in comparison to the strategies used during COVID-19. Data were analyzed through emerging themes from the documents. Therefore, the main themes aided to interpret the results. The results exposed dissimilar terms for blended learning such as F2F, hybrid, and the online teaching-learning process.The strategies used during COVID-19 were more advanced as compared to the past years. Traditional methods of blended learning included online sessions and face-to-face classes. Microsoft, Webinar, TREAD, zoom, and Google Classroom, and other applications have been commonly used throughout the COVID-19 affected countries. The formal institutions for the teaching-learning process to carry out in COVID-19 period frequently practiced some new strategies.
\end{abstract}

Keywords: Blended learning, formal, self-learning, hybrid, online learning. 


\section{Introduction}

Technology has become one of the most important factors in the implementation of numerous activities in the twenty-first century. The impact of progress in the twenty-first century may also be seen in the field of education, with technology-based learning. Teachers face a challenge as educators, as a result of the progress made in the twenty-first century, particularly when it comes to implementing learning through the use of technology. Elearning provides benefits, but making abrupt changes in the learning process and developing successful distant learning solutions are not as easy as it appears (Yastina,Syafii, \& Vebrianto,2020). As a result of COVID-19 Pandemic, All teaching and learning activities had to be done online using emergency remote teaching approaches, which necessitated a paradigm shift in pedagogy (Code, Ralph \& Forde, 2020). As a result, technology is a delivery method for remote education. Close coordination between teaching teams, material, and technology relevant to the 21st-century learning process is required for successful efforts to shift schools outside of traditional classrooms and buildings. The combination or mixture of online and offline learning activities is called Blended Learning, which is a learning strategy that combines face-to-face learning and learning that uses online learning resources (Yustina, Syafii, \&Vebrianto, 2020).

The Clayton Christensen academy describes blended learning as a 'structured educational program in which a student learns at least in part into internet-based content delivery and training with some characteristic of academic supervision from home. This process involved time, place, pattern, and careful monitoring facilities. It also encouraged the learners to feel more optimistic regarding their studies (Christensen, Horn, \&Staker, 2013).

The fundamental concept of driving blended learning is that it encourages a combination of self-learning and collective communication-oriented practices. However, during COVID-19 besides virtual and non-formal institutions, the formal educational institutes also moved to blended learning. As this was a new practice for the formal instructors and learners, therefore, this study was carried out.The study has been carried out for the assistances of policy makers, educationist and students. This study will empower them to employ blended learning strategies for the effective teaching learning process as well as to bond such strategies in a formal setting. This will specifically help during emergency situation.

\subsection{Purpose of the Study}

This work has been carried out for discovering the concept of blended learning with special reference to COVID-19 pandemic and for this purpose three sub purposes were:

1. To shed light on the concept of blended learning

2. To describe terminologies used for blended learning in the past and at present with special reference to COVID-19 Pandemic

3. To discover blended learning strategies with special reference to COVID-19.

\section{Literature Review}

Literature review comprised of four parts. Part first sheds light on the history of blended learning. The second part describes the concept of blended learning. But this part also sheds light upon some strategies of blended learning which were in practice in the past. The second part also describes different terminologies used for blended learning. Then blended learning strategies during COVID-19 are the final part of this literature. 


\subsection{Historical background of blended learning}

It was first used in the year 2000.A handbook in 2006 presented the educational implementation and issues of blended learning. Another impressive book was presented in 2008, which described the effective use of BL in higher education. Then its popularity leads instructors towards surveys for finding out about blended learning (Bernard, Borokhovski, Schmid, Tamim, \&Abrami, 2014).

\subsection{Concept of blended learning}

\subsubsection{Combination of online and face to face learning}

Blended learning is the "thoughtful fusion of face-to-face and online learning experiences that can be "learning-centered, with emphasis on active learning through collaboration and social construction of understanding (Colpitts, Usick, \& Eaton, 2020). Furthermore, it is the combination of face-to-face with online mode and side by side the application of e-learning strategies besides, traditional teaching-learning environment.

Teaching learning based on face to face and ICT

Combining different teaching methods i.e constructivism and

behaviorism for providing ICT based learning

Linking diffrent technological strategies

Linking $\mathrm{t}$ technology during teaching learning for creating a an effective teaching learning process

Figure 1(Uğur,Akkoyunlu, \& Kurbanoğlu,2011).

Analysis of a study showed that blended learning is a mixture of e-learning with traditional, face-to-face with online, mixing media, context, learning theories, pedagogies, and learning objectives (Oliver,\& Trigwell,2005). Authors described Flipped classroom as the type of blended learning. In this type of learning students have the opportunity for study materials and technical contents from outside the classroom. Diffrent modes used in this type of learning such as virtual platforms, sharing via clouds and LMS (learning management system). Similarly different methods used for engaging student like brainstorming, problemsolving discussions, promoting active learning in the presence of the teacher/mentor ( Ożadowicz, 2020).

\subsection{Effectiveness of blended learning}

Teachers can easily allow students to dig up much material via blended learning. Students do well on examinations when platforms are available in addition to traditional classroom materials, and when these materials are broadened to include more pertinent $\mathrm{e}$ resources. According to the 21st-century rules that graduates arising from the learning process must have ICT abilities, BL-based learning can boost students' enthusiasm in studying and train students' capacity to use ICT, make full use of the internet. The availability of online facilities and the experience of lecturers and students in online learning through a Management Learning System provide motivation and opportunities for students to become familiarised to think creatively with consideration of many sources, producing new works, modifying creativity, as well as truly new works. (MLS)(Yustina,Syafii,\& Vebrianto,2020). 


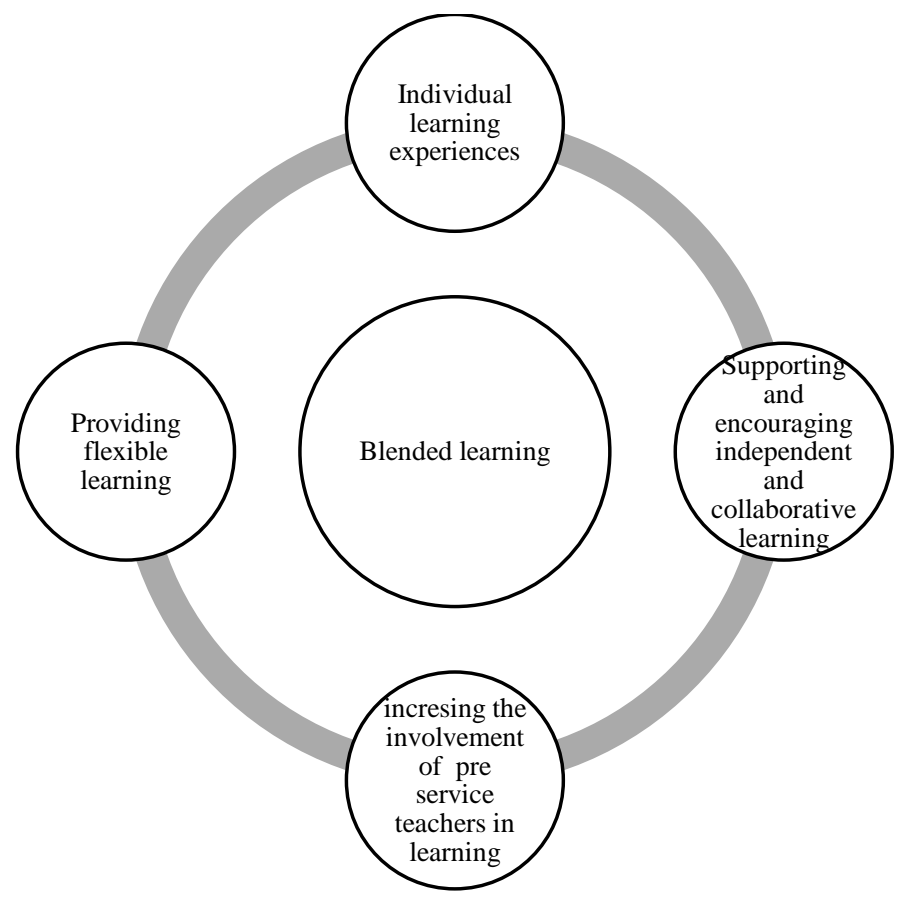

Figure 2 Effectiveness of blended learning (Martin et al, 2015 as cited in ((Yustina,Syafii,\& Vebrianto,2020).

Furthermore, results of the previous studies indicated that it is well documented that blended learning models offer substantial opportunity for incorporating flexibility, stimulating engagement, enabling students' learning, and improving learning outcomes. Changes in educational practice have prompted the rise of blended learning environments. Established educational practises are being adjusted, modified, and replaced. Conventional responsibilities, resources, and places are being transformed, enlarged, and supplemented (Boelens et al,2017,Hodges et al,2020,Zitter and Hoeve,20102 as cited in (Code,Ralph, \& Forde,2020).

Blended learning strategies are significantly more effective in improving student learning achievement and science process skills compared to conventional learning strategies. The use of blended learning is effective in improving student characteristics, interest and train them for using ICT. Furthermore, it fulfills all aspects that support the improvement of the quality of learning, provides many positive impacts on the learning process. It also has a significant role in creating learning patterns for pre-service teachers. However, expertise on the part of the educators for using ICT is important for the effectiveness of this system. Besides, different strategies also play an important role in interaction and communication with students. Student's creativity is directly related to the effective blended learning model (Yustina, Syafii, \&Vebrianto, 2020)(Yustina, Syafii, \&Vebrianto, 2020). The flexibility within blended programs allows for innovative supports, including collaborative cohorts (Colpitts, Usick,\&Eaton, 2020).

Previous studies revealed that $9 \%$ of university students believed that blended learning is more effective. However, providing skills for using different technological tools is a key element for the implementation of blended learning. In Blended learning contexts, motivation is also essential for best possible learning. Under such instructional situations, creating learning environments that support self-efficacy, stimulate curiosity and intrinsic motivation, and provide task value is likely to be highly beneficial. Furthermore, Blended learning tasks might include cooperative and collaborative learning opportunities. (Bernard, Borokhovski. Schmid, Tamim, \&Abrami, 2014). Previous study revealed that the students' 
view on the blended learning implementation is much more positive than traditional or elearning. Similarly other studies were also found showing a positive attitude of the student towards blended learning (Uğur, Akkoyunlu, \&Kurbanoğlu, 2011).

\subsection{Covid-19 and bleneded learning}

As we know that COVID-19 creates an environment in which everyone besides policy makers and university administration accept the reality for radical changes .So for the purpose to fulfill the educational aims, all the available technological resources were brought into action for the best possible communication at all levels. Furthermore experts try their best for discussing the traditional methods to updated methods of teaching and learning with a purpose to fulfill the communication gap. Likewise updated concepts related organization were also sought out for different levels. In this regard different innovative technological tools were developed for engaging students in an interesting way. The more effective and interest based technological tools were introduced in the form of mobile devices ,LMS and other platform based software.This is especially important in the light of the necessity to provide the most up-to-date technologies in technical courses, as well as increasing learners' skills in using portable devices and online technological materials(Ożadowicz, 2020).

\subsection{Traditional methods of bleneded learning before COVID-19}

Some traditional methods were found in a study related engineering filed. Such methods were as;

- Computer-based learning with software tools

- Technical knowledge and resources via web-based learning

- Online classroom and/or labs, establishing new types of environments for conducting experimentation, testing, prototyping, and ultimately online applications with scientific investigation

- Digital cooperation, allowing students, professors, instructors, and other, external professionals to share ideas and thoughts;

- Conventional face-to-face (f2f) programs with online technologies and tools (e.g., Power Point or Slide demonstrations and online assessments)(Ożadowicz, 2020).

\subsection{Blended learning strategies during COVID-19}

Previous studies showed that blended learning takes pattern but with the integration of technology.Various models were discovered to be successful, efficient, and appealing learning patterns based on students' desire in using intuitive media such as portable workstations and cellphones to better grasp theoretical information and resolve challenges linked to science learning. Websites, videos, and Learning Management Systems (LMS), Blogs, Wikis, and social media such as Twitter, Podcasts, MySpace, and Facebook are examples of technological media. A learning management system (LMS) is an application or programme that is used to manage online learning, which includes material, placement, management, and assessment (Yustina, Syafii, \&Vebrianto, 2020).

\subsection{Suggestions}

Based on the evidences from literature we identified different traditional and updated methods of blended learning specifically before and during COVID-19. But we found that authors suggested some additional knowledge and other skills for teachers and studuents for 
the effective blended learning activities. In this connection knowledge about the use and interaction with technological tools, organization of lectures and lab activities with updated technological tools by teachers and assistants and updating students regarding the effective use of technological tools are significantly essential (Ożadowicz, 2020). Garrison and Kanuka (2004) emphasised the importance of carefull integration of different learning modalities. Before implementing Blended Learning, they believe that planners should thoroughly evaluate the feasibility of merging both digital and face-to-face learning with current curriculum, resources, as well as other factors (Mahaye,2020).

\subsection{Theoretical framework}

For this study, we followed the current framework of Yousufzai and akhunzada (2020) in which they provide a framework for online learning during COVID-19. The study was beneficial and provided a base for our current study. Theoretical framework is shown in Figure 3.

\section{Methodology}

This study chartered a qualitative design with succeeding in the analysis of documents related to blended learning and how this strategy was used during COVID -19 for engaging the formal instructors with their students. The study was delimited to ten years documents (2011-20).The researchers' decision regarding delimitation and the selection of documents was based on their comprehensive study of the previous data. So, this study followed the current study of Yousfazi and Akhunzada (2020) and Shams,Ajmal and Jumani (2021) for methodology (Yousafzai \& Akhunzada, 2020), (Shams,Ajmal and Jumani, 2021).

\subsection{Sources of data collection}

- The study followed documents as "sources" as well as "text". Secondary sources were carried out in consideration. Furthermore text from the available online documents were searched and found not created (Kappinen \& Moe, 2012).

- The Study followed the ten years documents available online since 2011-20.

- The researcher's inquiry into ten years of data was for the purpose to discover the past strategies of blended learning in comparison to the strategies used during COVID-19.

\subsection{Data analysis}

- Data were analyzed through emerging themes from the documents. Therefore, the main themes aided to interpret the results.Three stages strategies for analysis was followed such as initial coding, organizing free codes into descriptive codes and then analytical codes. (Yousafzai\&Akhunzada,2020), Shams,Ajmal,Jumani,2021).

- During the first stage 28 free codes were identified which were organized as ten descriptive codes. Five main themes were identified from the descriptive codes such as the transformation of instruction, a combination of electronic methods, dissimilar terms for blended learning, dissimilar terms but the same concept, and advancement in technological apps during COVID-19. 


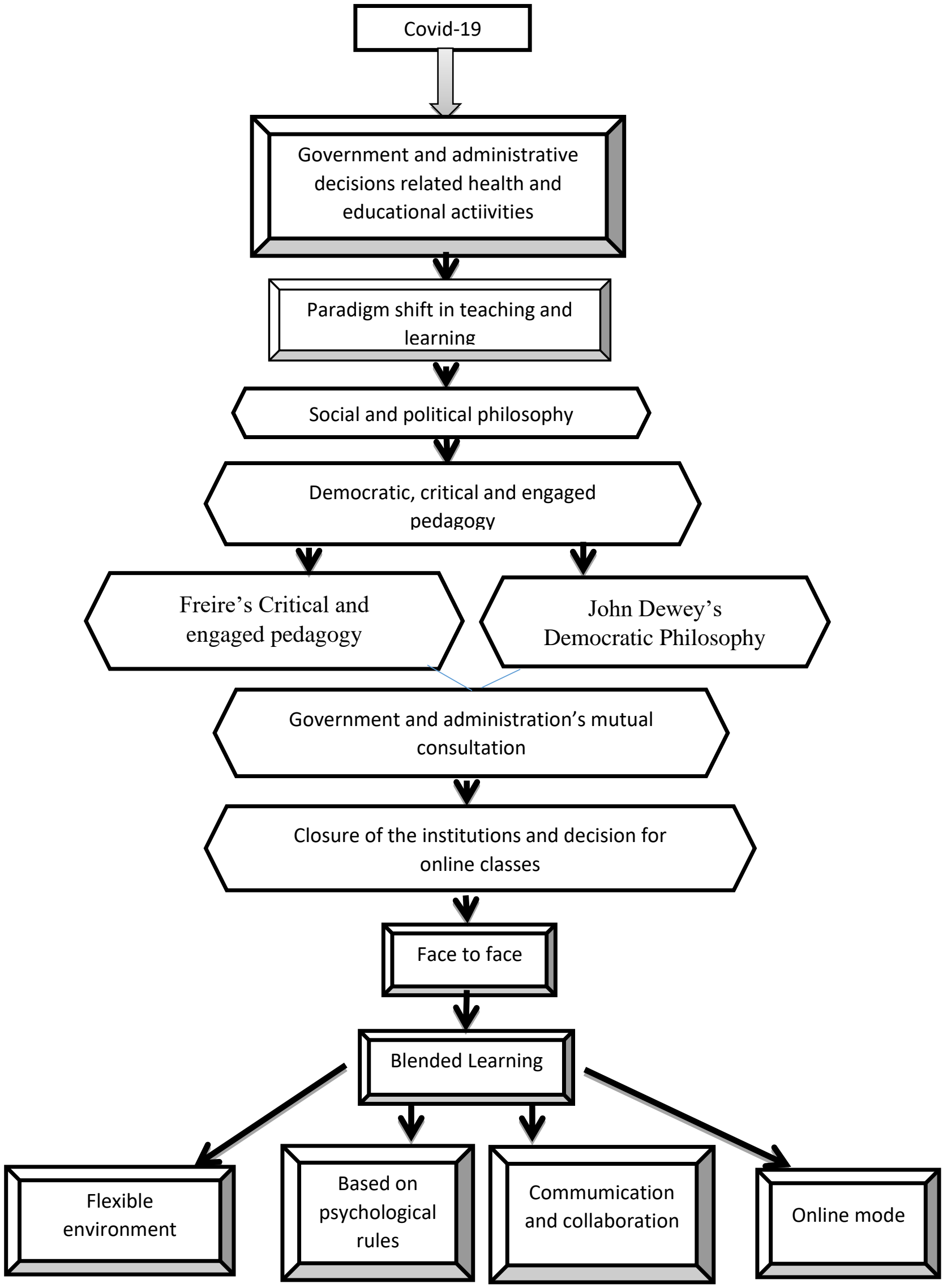

Figure 3Theoretical Framework 


\section{Findings and Conclusions}

Theme:1 Transformation of instruction

Theme:2Combination of elecctronic methods

Theme:3 Dissemilar terms for blended learning

Theme:4Dissimilar terms but the same concept

Theme:5 Advancement in techonological apps during COVID-19

\section{Figure 4 Themes}

\section{Theme I Transformation of instruction \& II Combination of electronic methods \\ Objective \#01}

- Blended learning is characterized mostly by a structured transformation of instruction consisting of both in-person classroom time and student online research through digital training programs. It is a form of a coordinated set of events that combines events, photos, recording, electronic functions, and face-to-face conversation that are teacher-led.
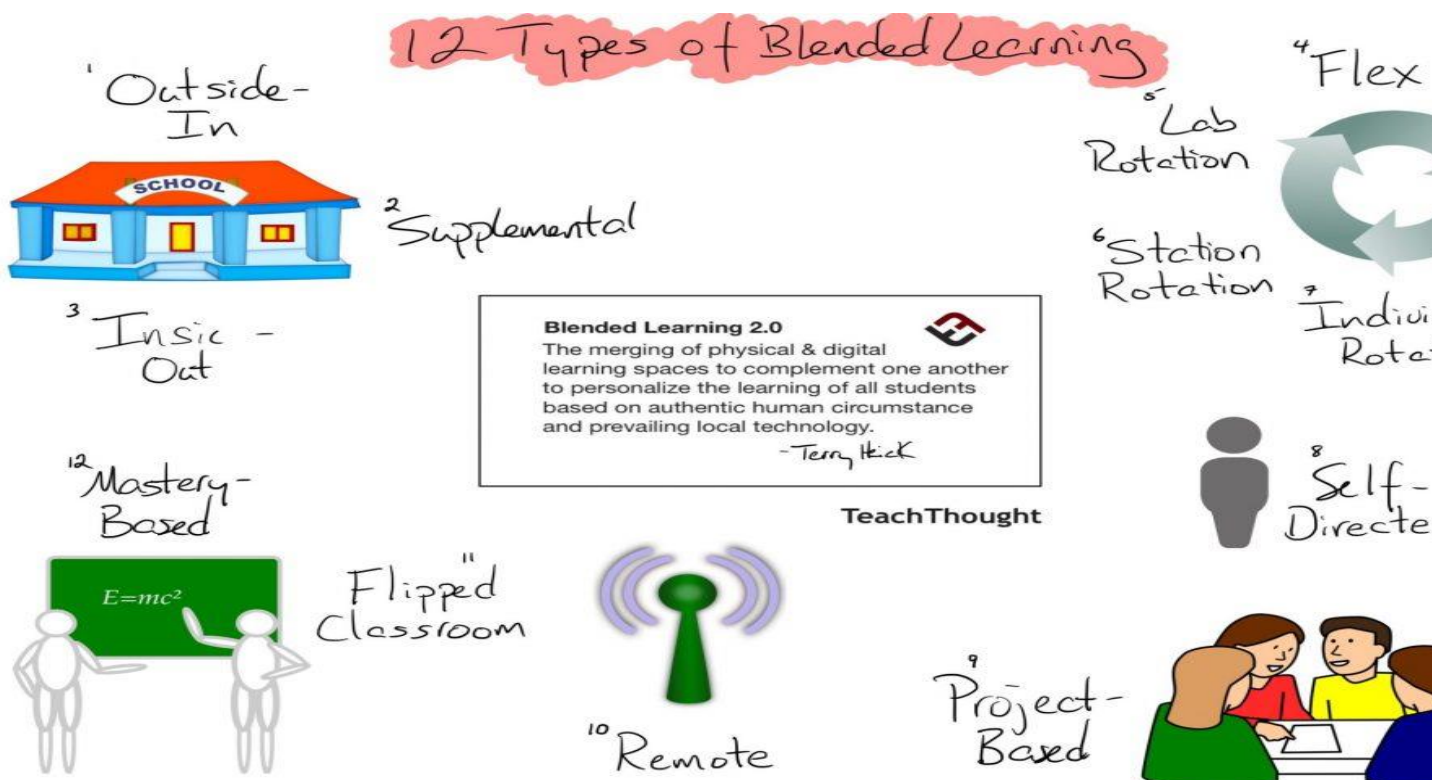

Station

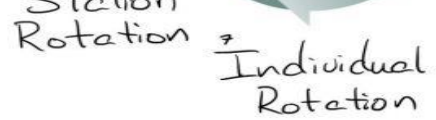

The another

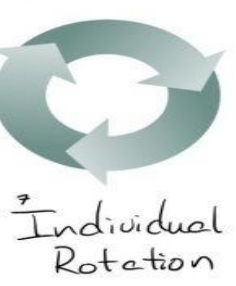

Figure 5 Types of Blended Learning("12 Different Types of Blended Learning", 2021).

\section{Theme III Dissimilar terms for blended learning \& IV Dissimilar terms but the same concepts}

\section{Objective \#02}

- The results exposed dissimilar terms for blended learning which has its roots in online learning.

- $\quad \mathrm{F} 2 \mathrm{~F}$, hybrid, offline, and online teaching-learning process.

- The result also exposed the concepts for blended learning as personalized and projectbased learning. 


\section{Theme: 5 Advancement in technological apps during COVID-19}

\section{Objective\# 03}

- The strategies used during COVID-19 were more advanced as compared to the past years.

- Traditional methods of blended learning included online sessions and face-to-face classes. Past blended learning strategies were also found as;

- Electronic whiteboards,

- Digital textbooks,

- Online lesson plans,

- Google Docs

- Webinar, TREAD, LMS, zoom, and Google Classroom, and other applications have been commonly used throughout the COVID-19 affected countries.

Some new strategies were frequently practiced by the formal institutions for the teaching-learning process in COVID-19 period.

\section{Recommendations}

- Teachers and students may transform blended learning from inactive to facilitating learning. So they may need to combine the online and face-to-face conversation into a new blended learning strategy.

- As we found that blended learning is a coordinated set of events so for adequate integration of teaching learning, practices are essential to provide expertise to all the blended learners.

- Findings revealed that COVID -19 startegies were not different from the past so the technological environment may be kept in mind for implementing blended learning strategies.

\section{References}

Bernard, R. M., Borokhovski, E., Schmid, R. F., Tamim, R. M., \&Abrami, P. C. (2014). Journal of Computing in Higher Education, 26(1), 87-122

Christensen, C. M., Horn, M. B., \&Staker, H. (2013). Is K-12 Blended Learning Disruptive? An Introduction to the Theory of Hybrids. Clayton Christensen Institute for Disruptive Innovation.

Colpitts, B. D., Usick, B. L., \& Eaton, S. E. (2020).Doctoral student reflections of blended learning before and during covid-19. Journal of Contemporary Education Theory \& Research (JCETR), 4(2), 3-11.

Code, J., Ralph, R., \& Forde, K. (2020). Pandemic designs for the future: perspectives of technology education teachers during COVID-19. Information and Learning Sciences.

Karppinen, K., \& Moe, H. (2012). What we talk about when we talk about document analysis. Trends in communication policy research: New theories, methods and subjects, 177-193.

Mahaye, N. E. (2020). The impact of COVID-19 pandemic on education: navigating forward the pedagogy of blended learning. Research online.

Lockee, B. B. (2020). Shifting digital, shifting context:(re) considering teacher professional development for online and blended learning in the COVID-19 era. Educational Technology Research and Development, 1-4.

Oliver, M., \&Trigwell, K. (2005). Can 'blended learning'be redeemed?. E learning and Digital Media, 2(1), 17-26. 
Ożadowicz, A. (2020). Modified Blended Learning in Engineering Higher Education during the COVID-19 Lockdown-Building Automation Courses Case Study. Education Sciences, 10(10), 292.

Shams, A., Ajmal, F. \&Jumani, N.B. (2021). Effectiveness of mobile learning for academic progress of MS Education students: A case study of distance learning program at IIUI. Pp 33-46.

Uğur, B., Akkoyunlu, B., \&Kurbanoğlu, S. (2011). Students’ opinions on blended learning and its implementation in terms of their learning styles. Education and Information Technologies, 16(1), 5-23.

Yustina, Y., Syafii, W., \&Vebrianto, R. (2020). The Effects of Blended Learning and Project- Based Learning on Pre-Service Biology Teachers' Creative Thinking Skills through Online Learning in the Covid-19 Pandemic. JurnalPendidikan IPA Indonesia, 9(3), 408-420.

12 Different Types of Blended Learning.(2021). Retrieved 16 March 2021, from https://www.teachthought.com/learning/12-types-of-blended-learning/.

Yousfzai,S.A,Akhunzada,S,A.(2020).Challenges and Responses of Higher Education institutions to align higher Education with COVID-19 Realities: A Thematic Analysis. International Journal of Distance Education and E- Learning (IJDEEL), VI( I) ,109-129. 